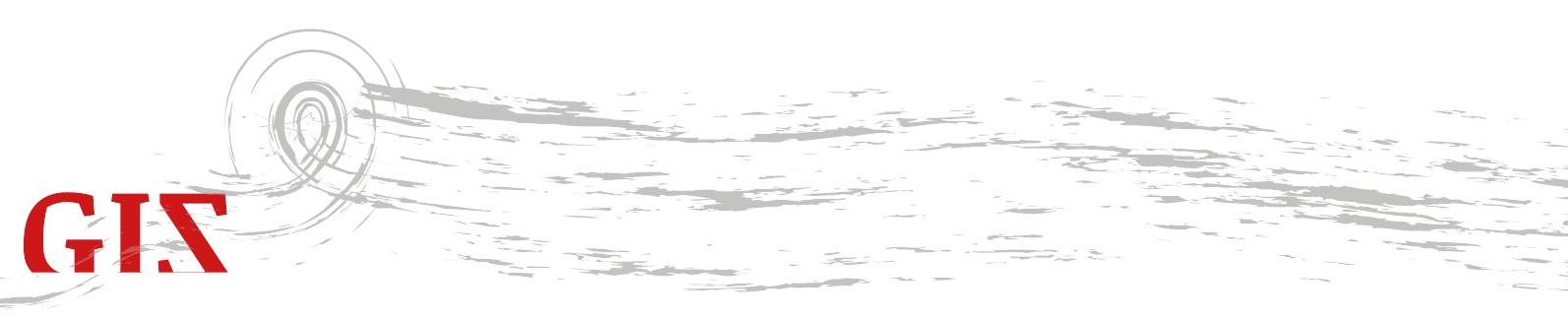

Faculdade de Comunicação Social

Cásper Líbero, São Paulo, Brasil.

\author{
ALEXANDER MAXIMILIAN \\ HINSELBECK FILHO ${ }^{1}$
}

\title{
O PASAMONTAÑAS COMO ESPELHO
}
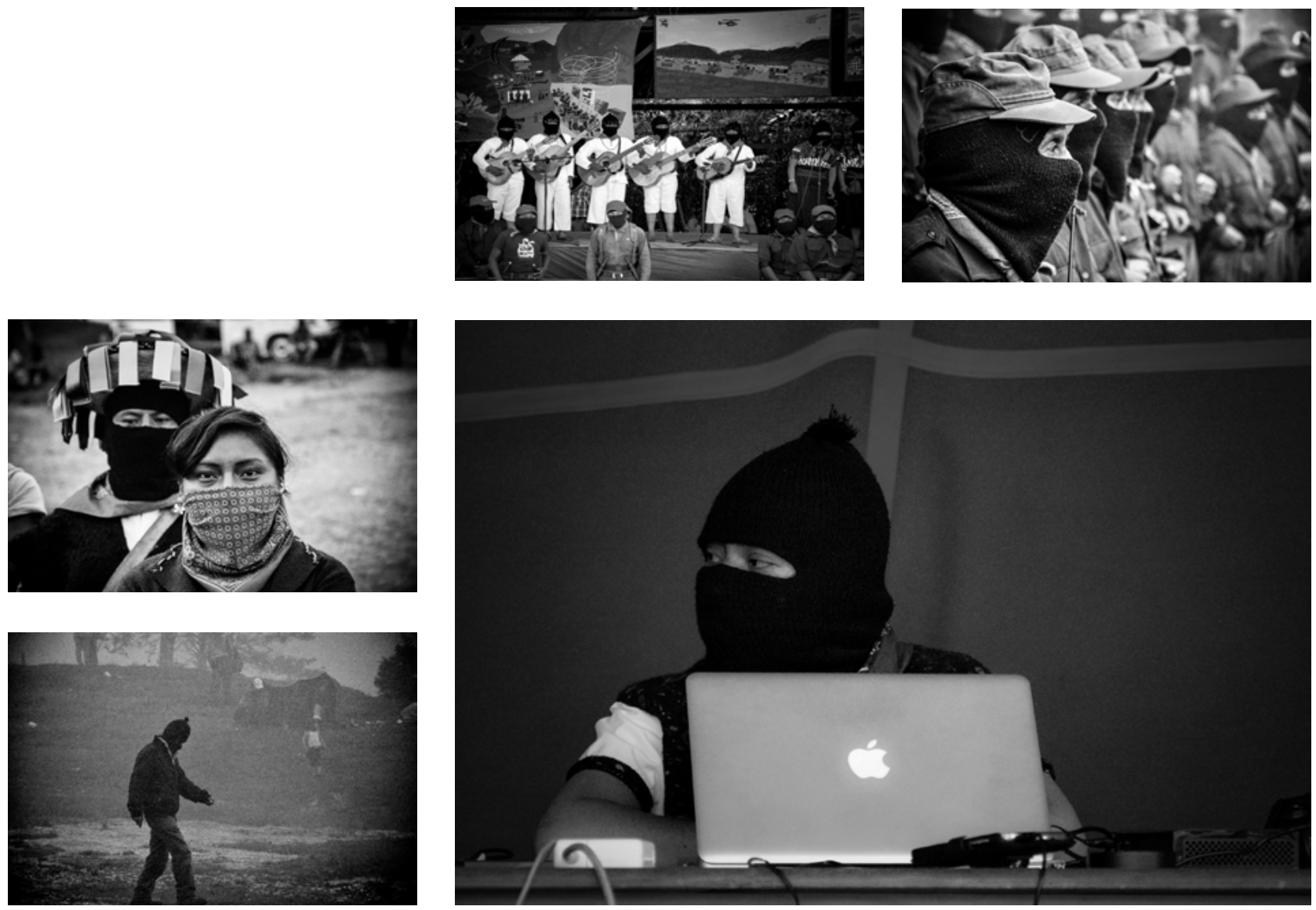

1. Fotografou as imagens em julho de 2017, no território autônomo zapatista Caracol de Oventik. Agradeço à viajante companhia de Suellen Abreu e de Raul Ruiz, bem como a imprescindível contribuição de Rafael Beverari com a edição das fotografias, mas, sou grato, sobretudo, às pessoas zapatistas, entre outros motivos por manterem vivas as chamas de resistência e dignidade, que elas possam nos inspirar. 


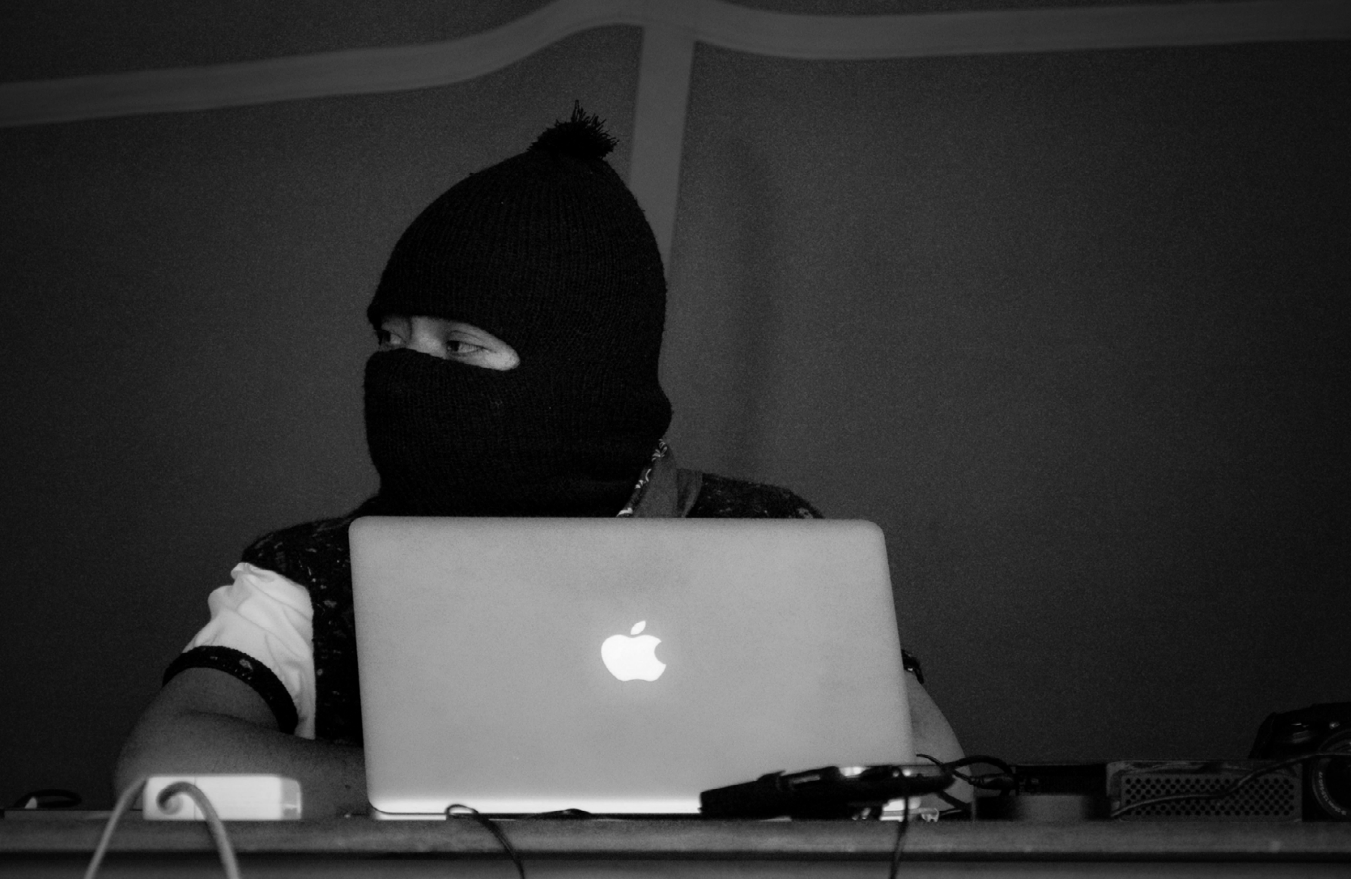




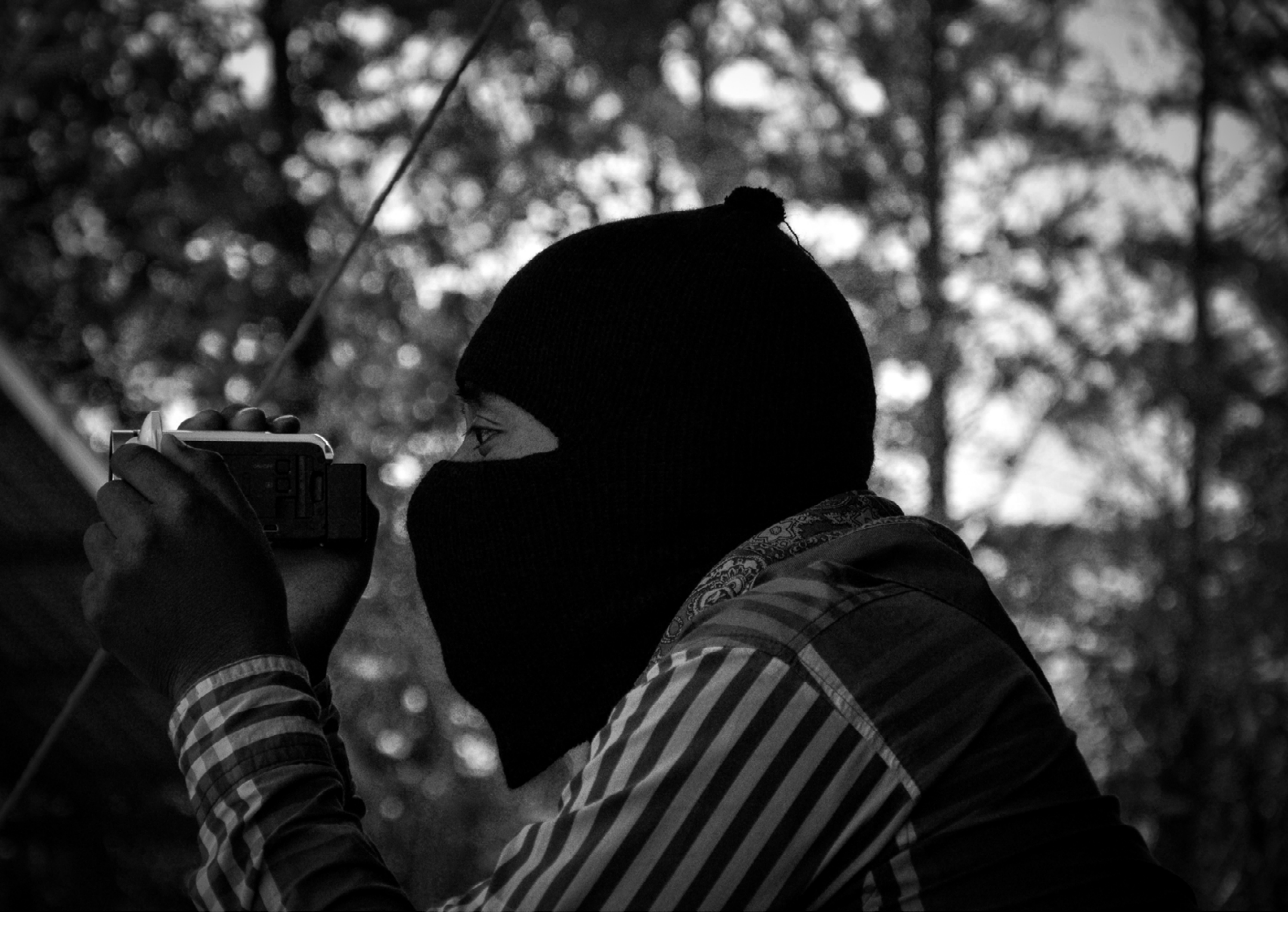


(1)

Q42
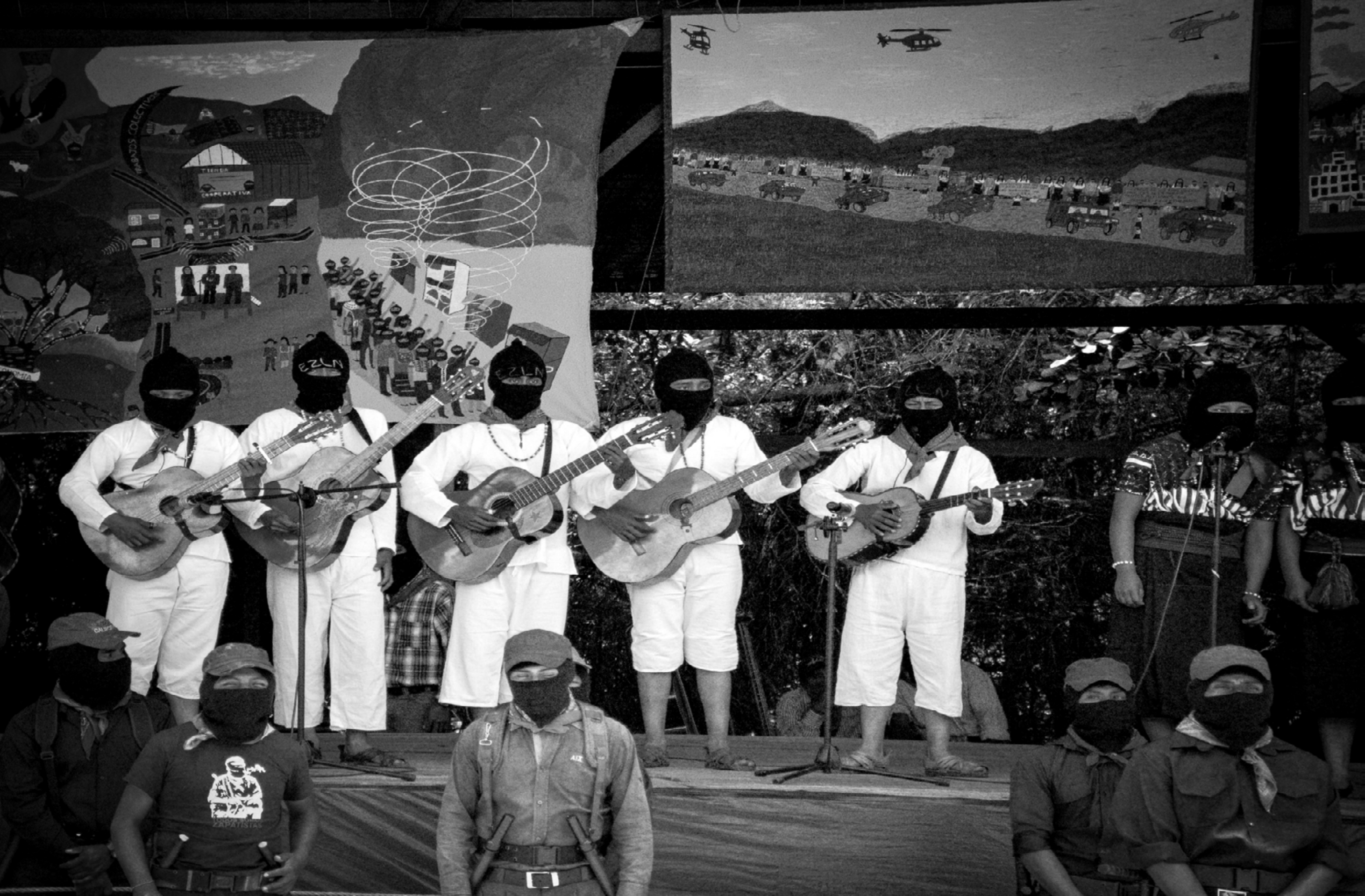



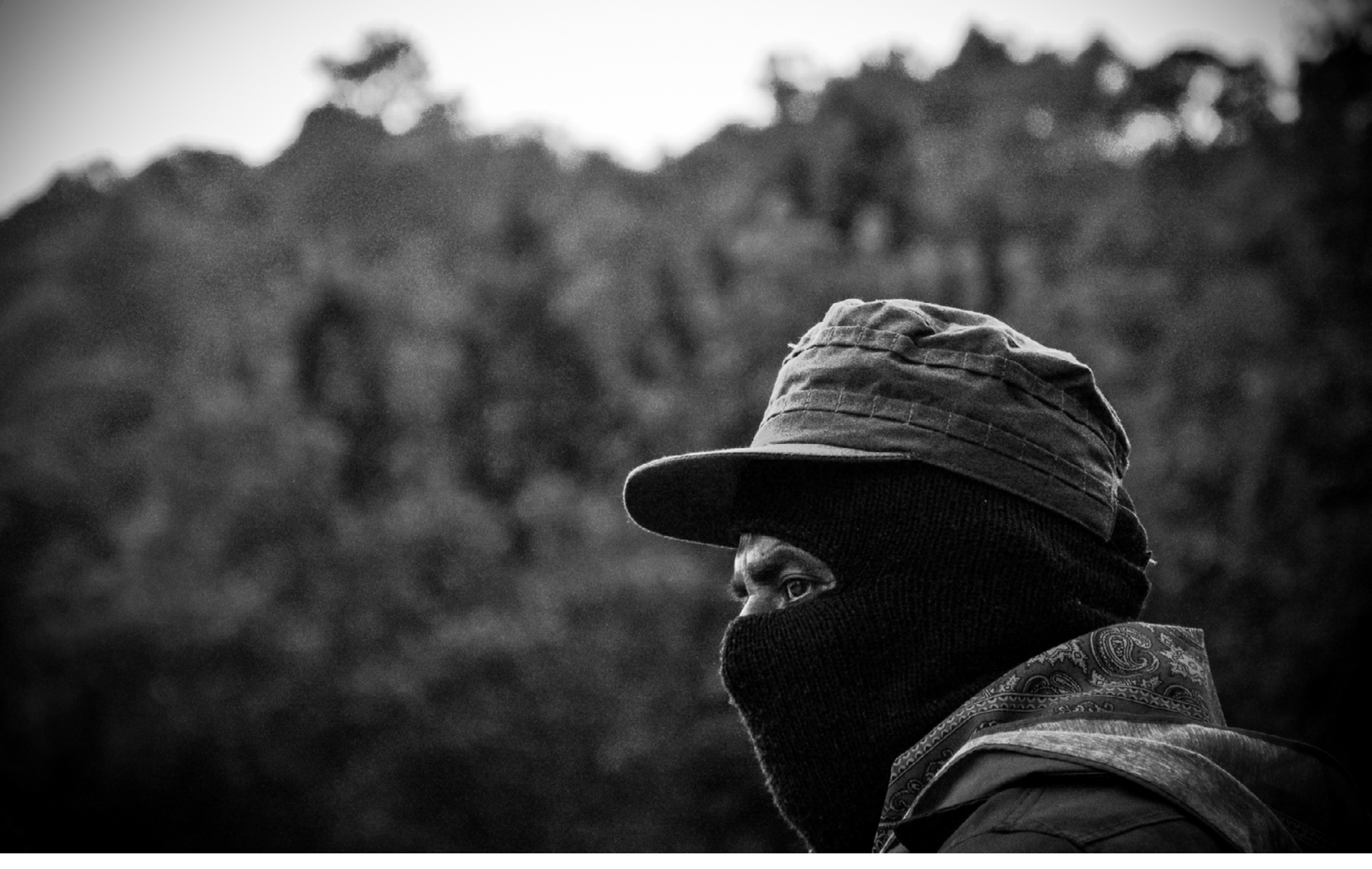




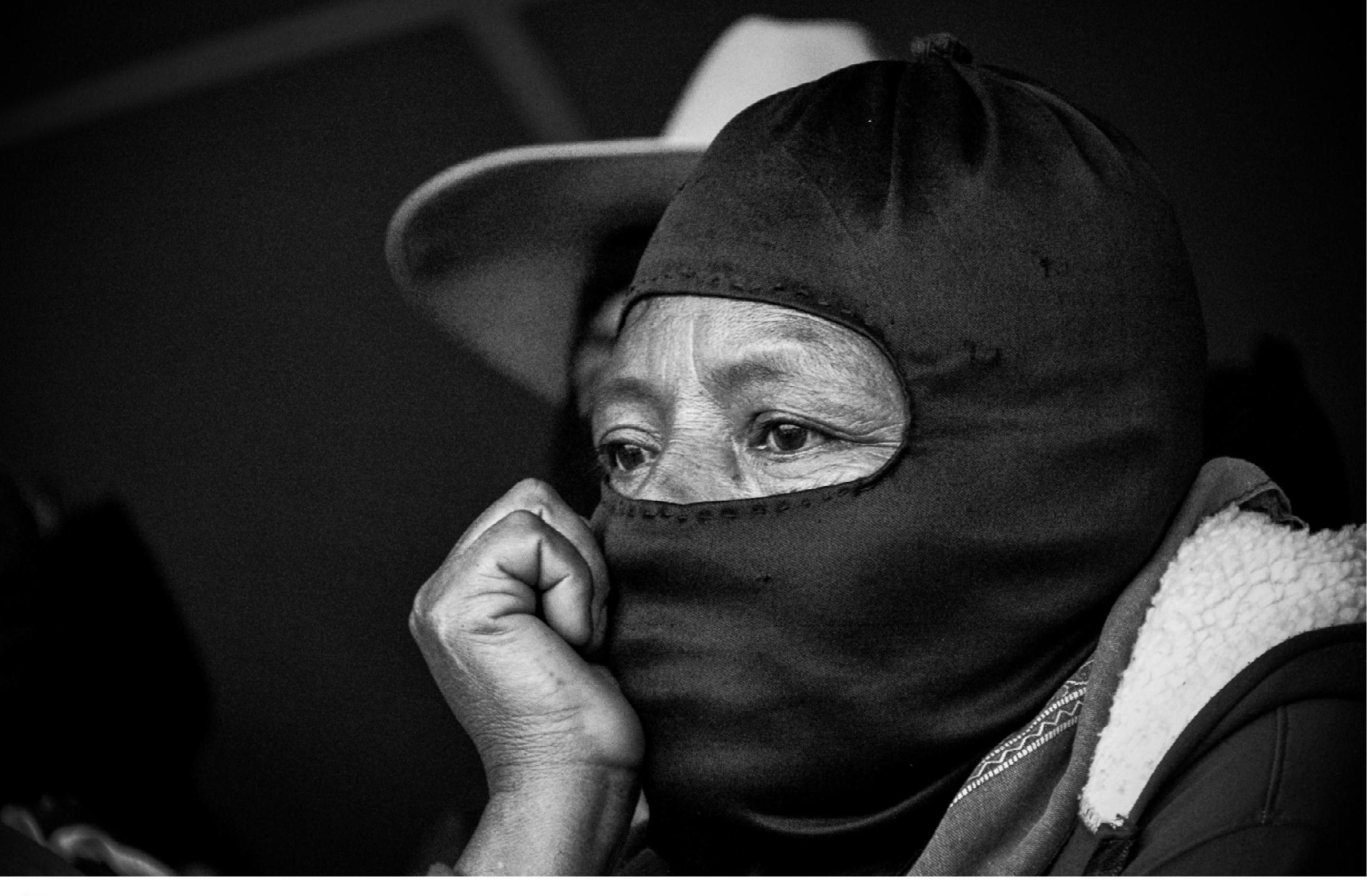




\section{$+2$}

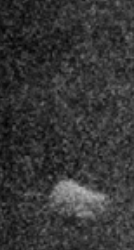

bs

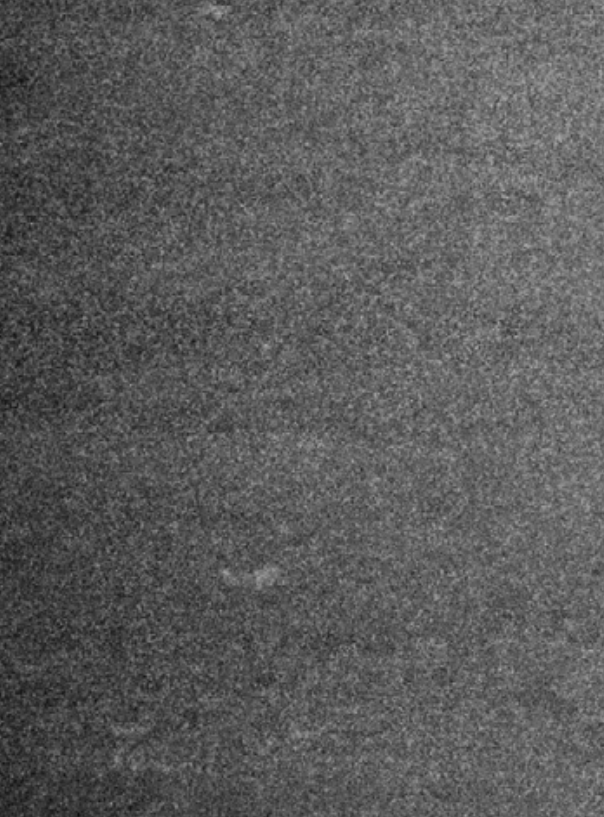

5

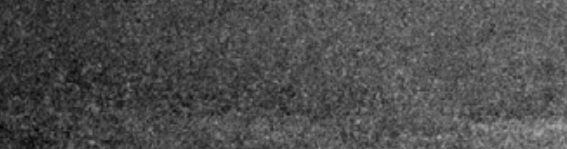

19.

(5)

$x=x^{2}$

ate

2.

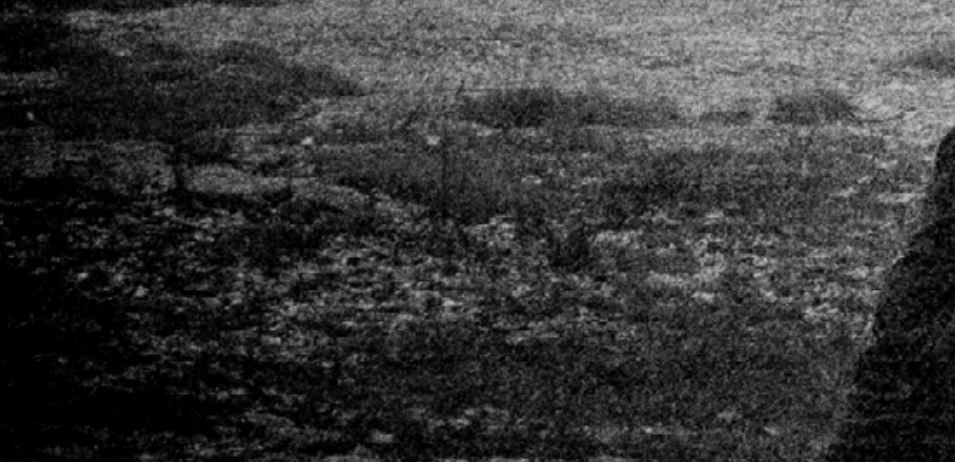


3.

$>$
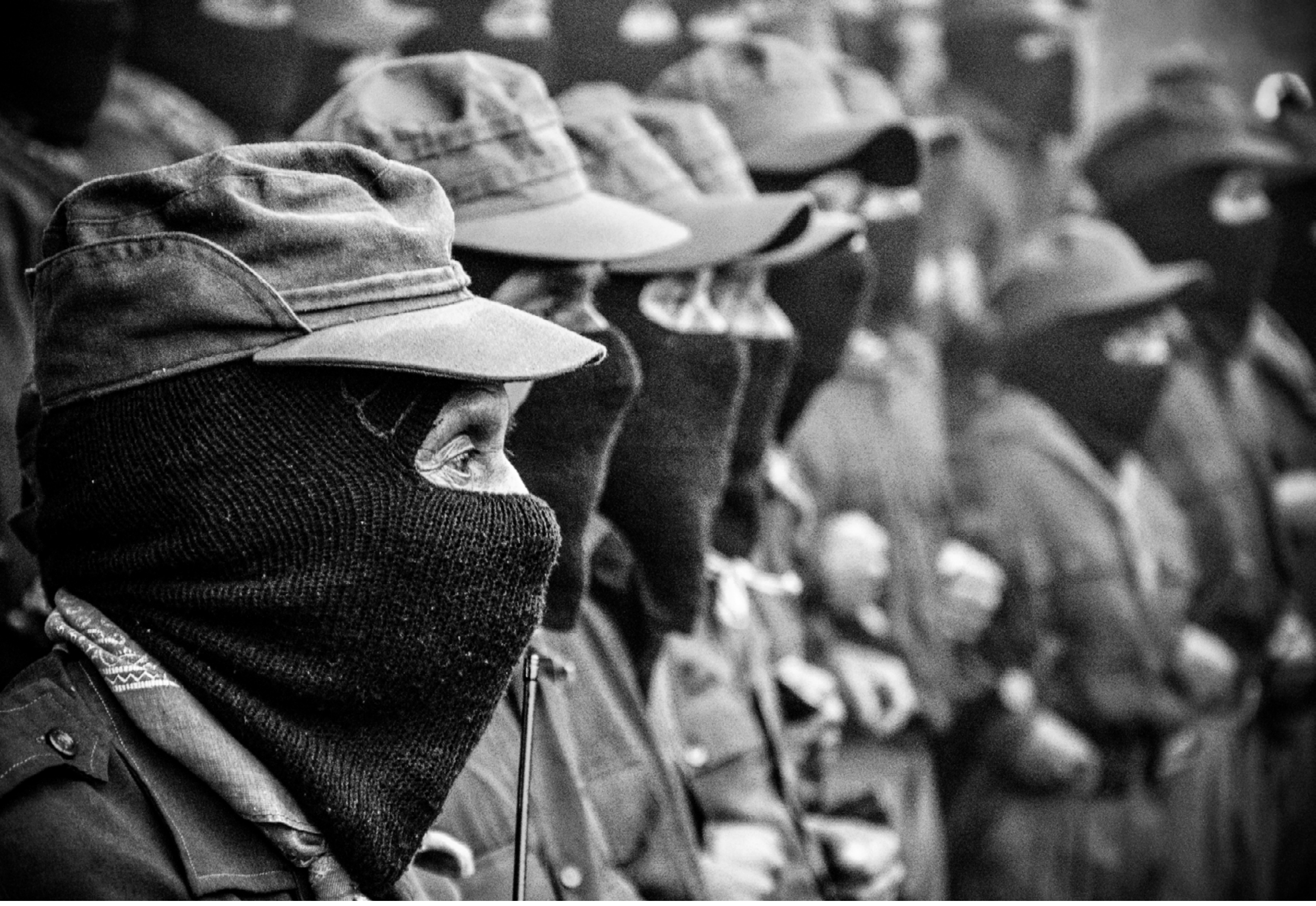


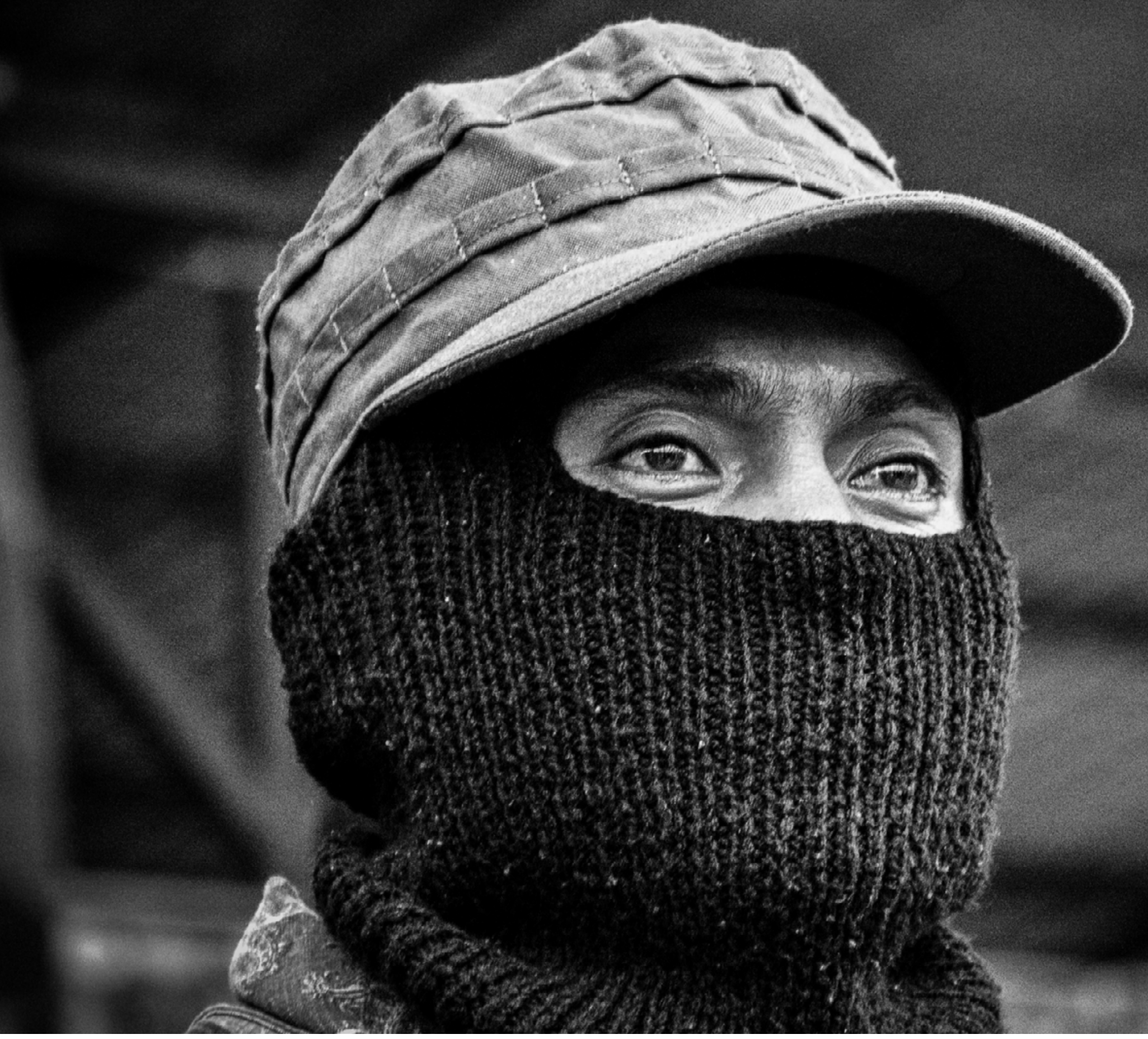




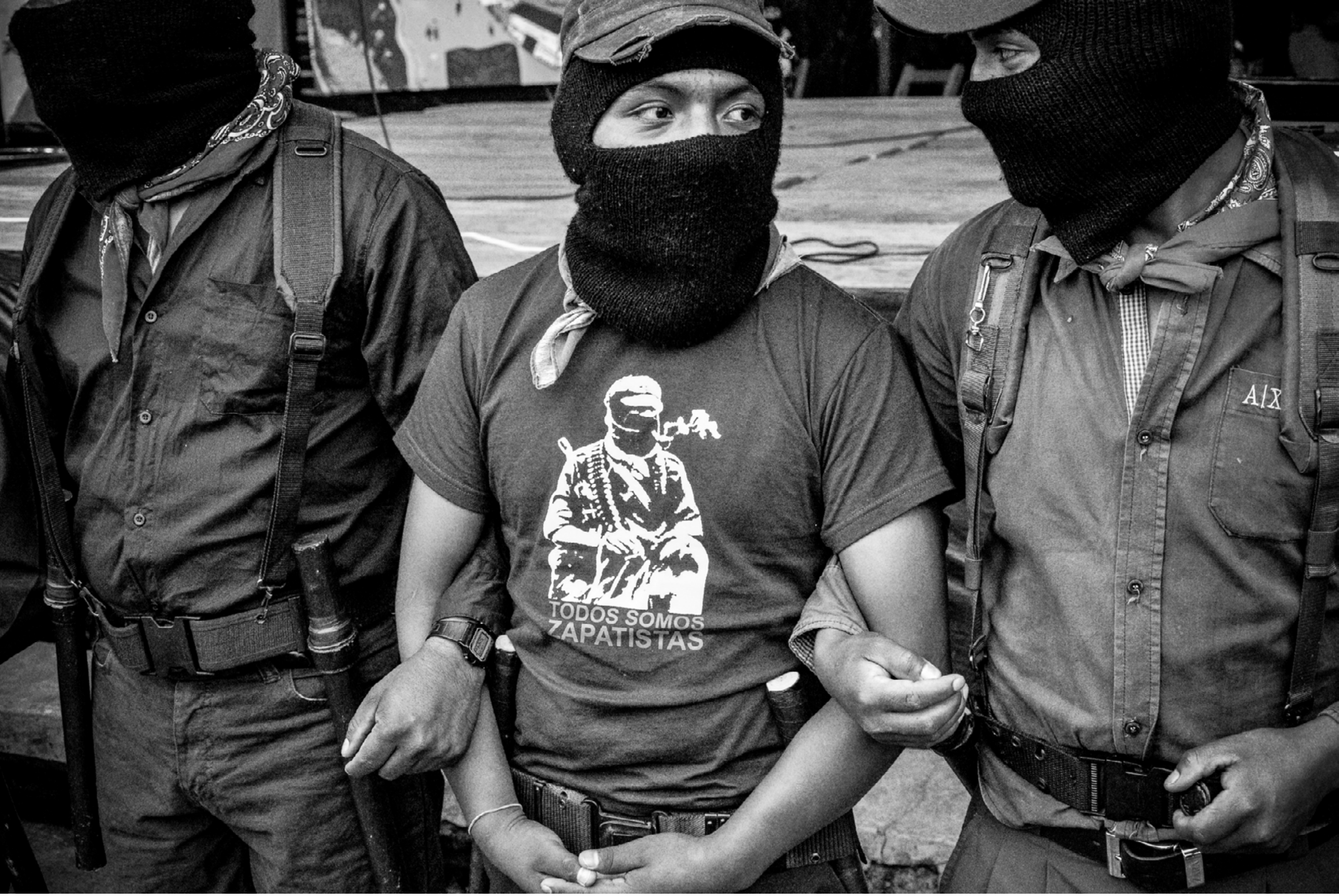




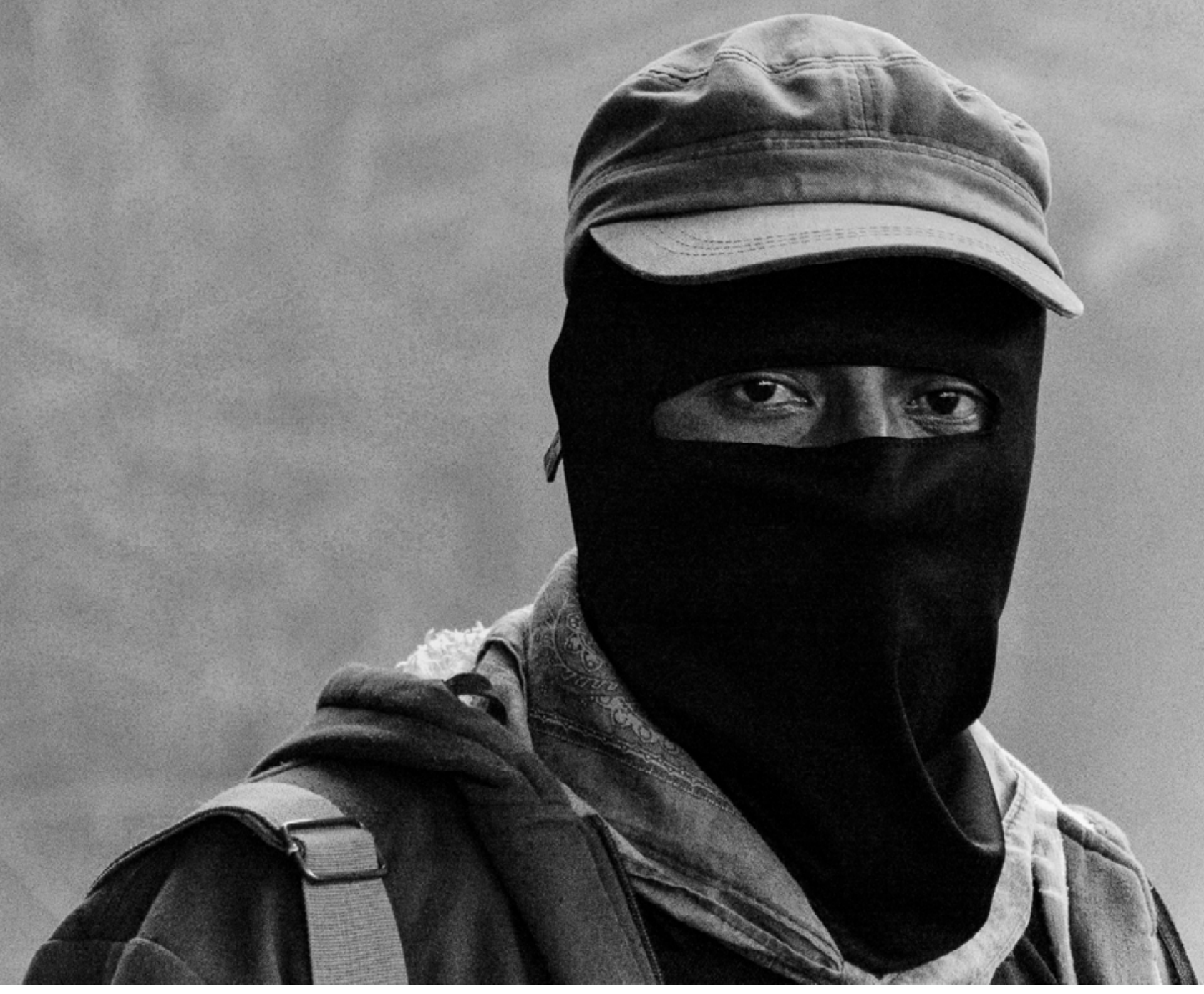


O atrativo do anonimato, do mistério, sem sobrenome, sem filiação conhecida, sem dados biográficos precisos.

Os rostos sempre cobertos pelo pasamontañas ou paliacates.

o que está para além das máscaras? Por que gorros e lenços geram tanta identificação?

Esses mesmos objetos que, ao esconderem as faces indígenas, "magicamente" transformam em visíveis os invisíveis de sempre?

Um dos motivos primeiros para a utilização dos pasamontañas (além de tentar se esconder do frio da região), foi o de evitar a repressão das forças governistas sobre os insurgentes e suas famílias, conseguindo, assim, a vantagem do mimetismo, isto é, de poderem assumir a condição de combatentes em determinado momento e, em outro, integrar-se à população civil. Aparecerem e desaparecerem na neblina e nas sombras da selva, na indiferença social que os fazem invisíveis.

Os pasamontañas e paliacates se transformaram em símbolo de rebeldia da luta zapatista.

Esse simbolismo foi rapidamente percebido pelos insurgentes e utilizado como um dos inovadores expedientes dramáticos e de performance da insurreição.

O uso dos pasamantañas foi atrelado pelos zapatistas a significados múltiplos, como de não personificação de sua luta, na qual todos se identificam como um, sem protagonismos (Hilsenbeck Filho 2007).

Eles ainda subverteram símbolos indígenas ancestrais, em que as máscaras serviam para imputar o terror. Ressignificaram outros, em que elas simbolizavam o retorno dos antepassados (Colombres 2014). Agora, o pasamontañas esconde os mortos em vida, os mortos de sempre, sem paz, que renascem na luta para viverem, enfim, numa busca de vida e morte com dignidade.

Uma das metáforas mais populares, construída pelo então porta-voz e chefe militar do Exército Zapatista de Libertação Nacional, Subcomandante Insurgente Marcos, é a de que os pasamontañas servem como espelhos, em que o país enxerga seus problemas e lhe interroga uma solução. Nesse espelho a nação pode se olhar e identificar-se com os insurgentes, com os sem-rosto que tiveram que esconder suas faces indígenas para se fazerem visíveis.

Os instantes deste ensaio foram fotografados durante o I Festival CompArte pela Humanidade, em julho de 2016, momento em que as comunidades zapatistas do sudeste mexicano, pela primeira vez, abriram seus 
territórios para mostrar e compartilhar com trabalhadores da arte de outros cantos do mundo seus fazeres artísticos.

Às vezes os olhares miram o chão, noutras ocupam o lugar da palavra, enviam mensagens, ensaiam acordes e danças, demonstram união e solidariedade. Na maioria das vezes os olhares interrogam à alma, indagando as possibilidades abertas à construção de outro mundo, um mundo onde caibam muitos mundos.

Nós as zapatistas, os zapatistas, não olhamos para cima.

Apenas frente às ciências e às artes levantamos nossos olhos, nossos ouvidos. E não são o temor e a obediência as que, assim, levantam nosso olhar. É a potência do conhecimento, é a maravilha das artes. [...] ainda que seja na fugacidade de uma peça musical, um traço de pintura, um passo de baile, um fotograma, uma linha de um diálogo, um verso, um o que seja, seja derrotada a hora da polícia, e em um segundo ao menos se respire a possibilidade de outro mundo (¿La geografía?... 2016).

\section{REFERÊNCIAS BIBLIOGRÁFICAS}

¿La geografía? Oventik. ¿El calendario? 29 de julio del 2016. 2016. Enlace Zapatista, 17 jul. 2016. Disponivel em: <https://goo.gl/NA4L38>. Acesso em: 5 dez. 2017.

Colombres, Adolfo. 2014. Teoría transcultural del arte: hacia un pensamiento visual independiente. México: Conaculta.

Hilsenbeck Filho, Alexander Maximilian. 2007. Abaixo e à esquerda: uma análise históricosocial da práxis do Exército Zapatista de Libertação Nacional. Dissertação de mestrado, Universidade Estadual Paulista Júlio de Mesquita Filho, Marília. Disponível em: <https://goo.gl/BXjoNT>. Acesso em: 5 dez. 2017.

recebido

17.03.2017 aprovado

02.08.2017

\section{ALEXANDER MAXIMILIAN HILSENBECK FILHO}

É professor de Ciência Política e Cultura Brasileira na Faculdade de Comunicação Social Cásper Líbero (FCL), instituição que auxiliou esta pesquisa através de seu Centro Integrado de Pesquisa. Doutor em Ciência Política (Unicamp) investigou dilemas do Movimento dos Trabalhadores Rurais Sem Terra; Mestre em Ciências Sociais (Unesp) com trabalho sobre a práxis do Exército Zapatista de Libertação Nacional; Bacharel e Licenciado em Ciências Sociais (Unesp); está como pesquisador no: NEILS; GT ACySE-CLACSO; Grupo de Comunicação, Política e Sociedade do Espetáculo da Cásper Líbero. 